\title{
XXV.-THE TEACHING OF MEDICINE.
}

By Dr. EDWIN MATTHEW, Assistant Physician, Royal Infirmary.

\section{(A) The Teaching Arrangements in Medicine.}

DURING the past eighteen months the assistant physicians to the Royal Infirmary have had under consideration the present teaching arrangements in medicine and the present state of hospital equipment in relation to this teaching. Certain defects were noted and discussed, and it was recognised that various improvements might with advantage be made. The invitation of the Pathological Club to contribute a paper on the teaching of medicine has afforded them the opportunity of presenting the conclusions unanimously arrived at, and by arrangement these conclusions and the recommendations arising out of them are presented in
this paper.*

The efficiency and status of the Edinburgh Medical School largely depend on the standard set by the teachers of clinical medicine and surgery. The function of the school is to turn out thoroughly qualified practical men, well versed in modern methods of investigating and treating disease in its early and late stages-men imbued with a desire to help in advancing our knowledge of disease, recognising that in many directions their aid is both necessary and valuable.

The existing system is, in many directions, defective, and its defects are largely responsible for the dissatisfaction-openly expressed by some and felt by most-with the position and aims of the medical school at the present time. The assistant physicians frankly admit their share of responsibility in this matter, and are only anxious to have it corrected with as little delay as possible. The defects in the present system include: $(a)$ Defects in the teaching arrangements proper, and $(b)$ defects in equipment, which limit the efficiency of the teaching. The subject may be discussed conveniently under these
two heads.

Teaching Arrangements-1. Systematic Medicine.-The systematic lecture has always been the basis of teaching in all subjects of the medical curriculum. The system has much in its favour, but as in other subjects, so in medicine, the systematic lecture can be overdone. If the aim is to give the student, in a course of one hundred lectures, a more or less complete account of diseased conditions-their recognition, results, and treatment-the method must necessarily resolve itself into a mere dictation exercise, with little benefit to the student. (For this purpose

" Dr. Ritchie, absent on military duty, took no part in these deliberations; Dr. Goodall, up to the date of his departure on war service a few months ago,
was in complete general agreement with his colleagues. 
one or other of the many excellent text-books can be utilised.) The duties of the professor might with advantage be considerably lightened, in so far as the number of systematic lectures is concerned; the course of instruction would greatly benefit thereby. Tuberculosis now has a chair to itself ; fevers are fully dealt with elsewhere; there is a compulsory course on diseases of the skin. Much more attention should be paid to therapeutics, including general therapeutics, physical therapeutics, and dietetics; these should, so far as definite instruction is concerned, be taken in a separate course. The lectures in medicine could thus be reduced say to fifty, not necessarily delivered consecutively, and the remaining time be devoted to more practical work; there are many subjects in medicine which can be taught practically by the Professor of Systematic Medicine. For this purpose the professor should have more assistance ; a scheme might be devised whereby the clinical tutors would be available for this work. In addition, the professor of medicine should take cognisance of two special branches of medicine which we believe are entirely neglected, viz. psychology in relation to medicine and medical ethics.

2. Clinical Medicine. - Instruction in clinical medicine includes clinical lectures, bedside cliniques, instruction in the medical out-patient department, clinical tutorial instruction, and dispensary practice. These will be considered seriatim.

(a) Clinical Lectures.-The arrangement recently adopted of having separate lectures for juniors and seniors is the only feasible one, and should be strictly adhered to, a senior student being defined as one who has attended bedside cliniques for six months. Lectures are delivered twice a week by the lecturers in rotation. At present each lecturer is in a compartment by himself, and, more or less, lectures. independently of his colleagues. In our opinion the subjects for lecture should be carefully considered by the Clinical Board, and at the beginning of the session a syllabus should be drawn up of lectures suitable for junior and senior students. It is possible to draw up a scheme of lectures which would be a great advance on the present system, a scheme which would still give the physician in charge a really free band in the choice of subjects.

(b) Bedside Cliniques. - The best results from teaching at the bedside can, in our view, only be obtained under the following conditions:-

1. The separation of junior and senior students. In the university calendar, under clinical medicine, it is stated that clinical lectures are delivered to senior and junior students separately; it would be well if the word "separately" were also included under bedside instruction.

2. By limitation of the cliniques. This was laid down as a regulation by the teaching staff about six years ago, but never effectively carried out. Only in this way can the student see and hear what he is meant to see and hear; also, in a limited clinique, the teacher can 
quickly appreciate and discriminate the different grades of intelligence among the students. Any number greater than twenty-five is too large. Of course, if the total number of either junior or senior students exceeds 150 , then each clinique will have to be proportionately

3. That attendance by the students be regularly ascertained and enforced. If the clinical teacher has his responsibilities so has the student; he should be encouraged to be in the wards as much as possible, and also urged to observe and learn for himself, and not depend alone for his clinical knowledge on what he hears at clinique; he should be made to verify facts for himself by repeated examination, and time should be available for this.

4. The case records of the students should be taken into consideration in regard to qualifying certificates. The junior house physician should be responsible for assisting the students in case-taking, and the cases should be read and examined by the physician in charge. A student's work during his qualifying nine months-his records of cases, his attendance at cliniques and in the wards-should be available for reference and taken into consideration at the final examination.

5. Cliniques, for the junior student especially, should be more systematised. Haphazard choosing of cases for clinique, because they are good cases, does not give the student the proper grasp which orderly instruction in the various conditions of the different systems would. It is possible that at any one time suitable material is not available in any one charge for orderly instruction of systems, but it should be possible to make arrangements whereby the material in all the wards is open
to every teacher for clinique purposes.

(c) Medical Out-Patient Department.-In recent years the arrangements in the medical out-patient department have, from the teaching standpoint, been far from satisfactory. Students drop in at all times -students who have done no clinical medicine, students who have done three months, six months, or nine months, and graduates. Effective teaching cannot be carried on under such conditions. The clinique should be restricted to senior students, those attached to a particular charge receiving out-patient instruction on the day the physician is waiting. An attempt has been made, beginning in January of this year, to organise such a clinique, but unfortunately, and wrongly we think, junior students have been instructed to attend. In our view, attendance at out-patient cliniques is not for the student who is still unfamiliar with the ordinary physical signs of disease.

(d) Clinical Tutorials. - A large part of the work of the tutor should be the personal supervision of the side-room work done by the student on his cases. The work should be of a very individual nature, as little class instruction as possible being included. If the curriculum would allow, it would be a great advantage for the student to have a short 
course of instruction in physical methods prior to commencing ward work proper. This course would be devoted exclusively to methods of examination and physical signs present in health. The clinical tutor might with advantage have the assistance of senior student demonstrators in this course.

(e) Dispensary Teaching.-Dispensary practice is of great value to the student. A great part of his afterwork consists in the recognition and treatment of minor maladies, which he does not and cannot see in the wards of the Infirmary, but which are of everyday occurrence in Dispensary practice. Dispensary teaching should be definitely co-ordinated with the teaching in the Infirmary, and, in addition, the teaching in the Dispensary should be devised to meet this. If this arrangement were carried out, the teaching of medicine from the curative point of view could be brought into line with teaching from the preventive point of view. We concur in the advisability of this course as outlined by Dr. Robertson in the discussion on Preventive Medicine.

Final Examination in Medicine.-After a compulsory nine months' instruction in clinical medicine the student proceeds to his final examination. This examination, we believe, is not adequate, being too short and too casual, and it is doubtful if the fairest and best results are at present obtained. Longer time should be given to the oral examination of each student, and the examination in special or side-room work should be extended. This implies that the final examination should either extend over a longer time, or that more examiners be employed. In our opinion both are necessary, and we believe this can be easily met by appointing as examiners all the teachers in the Infirmary, both physicians and assistant physicians. We believe that the raising of the standard of the final examination on the above lines would be of great value in assuring the student's attendance at, and work in, the medical wards and side-rooms.

Before leaving this part of the subject, I may add that we are aware that in the last year or two the whole subject of the more efficient teaching of medicine has been under the consideration of the medical faculty, and a report was drawn up by them embodying certain recommendations which it was suggested should come into force after the war. This report was, we understand, in general approved of by the Board of Studies last year. We have recently had an opportunity of seeing this memorandum, and find that many of the recommendations in it are identical with those independently arrived at by us, and presented above.

I pass now to another aspect of teaching of very special importance to the medical school, namely, that of Hospital Equipment in Relation to Teaching. 


\section{(B) Equipuent in Relation to Teaching.}

Modern and adequate equipment are absolutely necessary for efficient teaching. Unless adequate facilities for the diagnosis and treatment of disease are provided it is impossible for the clinical teacher to give adequate instruction in modern medicine, or to stimulate the interest of the students in the practical application of the instruction that they have previously received in their earlier subjects. We shall refer briefly to the changes we think necessary for improving the facilities for teaching, and for the adequate treatment of patients in the Infirmary.

1. Dental Department. - In a hospital of 900 beds a large number of patients suffer from septic conditions of the mouth, which may have a considerable bearing on the etiology of many diseases of unknown origin in the wards. This necessitates a larger staff of dental surgeons and greater facilities for treating patients in the hospital. The staff has recently submitted to the manager a scheme for improving this department, which, if carried out, will modernise the teaching and
make it more effective.

2. Massage and Physical Therapeutics.-The present arrangements for the treatment of patients are unsatisfactory alike from the point of view of the patients and the students. Recently the assistant physicians submitted a memorandum on this subject. If the scheme proposed in this memorandum is carried into effect, facilities will be available both for the efficient treatment of the patients and for giving the students a reasonable minimum of instruction in this
important subject.

3. Balneological Department.-This department is at present in abeyance on account of the war. Its equipment and organisation in pre-war days was not such as to allow any adequate instruction in the subject being available for students. The complete reorganisation of
the department is essential.

4. Facilities for Bacteriological Investigation._-Much consideration bas been given by the assistant physicians in the course of the past year to this subject, and, as a result, a report, representing the unanimous opinion and recommendations of the assistant physicians, was recently submitted to their senior colleagues for their consideration. In this report it was pointed out that while the appointment of a clinical pathologist, five years ago, had greatly increased the efficiency of the work done in the institution, the great development of bacteriological science in relation to clinical medicine now necessitates a further the following obsersion for clinical investigation. This report included 


\section{"Bacteriological Investigation in. Medicine.}

"Every physician is daily brought in contact with many diseases, the cause of which is unknown, and the results of treatment of which are extremely unsatisfactory. As examples, we may cite rheumatoid arthritis, pernicious anæmia, certain forms of nephritis, and of disorder of the intestinal tract. The defects of our present knowledge of the diagnosis and treatment of these disorders, and of the conditions of their development, make it essential that increased facilities be obtainable for their more special investigation, and for the teaching of the students.

"There are many chemical problems in connection with the examination of pathological secretions-notably the urine, effusions into the pleural and peritoneal cavities, and cerebro-spinal fluid-as well as in disorders of respiration, blood conditions, and conditions of metabolism, that cannot be adequately observed under existing conditions. If the data required for a diagnosis according to modern methods are to be available, additional expert assistance from the chemical standpoint is a necessity.

"It is impossible for the present staff of the pathological department to overtake fully the investigation of problems which require extended observations. For this purpose it is necessary that the clinicians who require to make such observations should be provided with assistants for this purpose. It is suggested that the Infirmary Board should agree to appoint honorary officers, who should be graduates in medicine, with a recognised status. An appropriate name for these officers would be Clinical Observers. The officer would be appointed by the Infirmary Board on the application of a member of the clinical staff. His duties would be to investigate definite problems under the direction of the clinician who makes the application. The co-speration of the professors of pathology, bacteriology, or medical chemistry would be available in cases where the investigation involved the application of special laboratory methods, and they would direct the investigations in their respective laboratories. The clinical observer should not be responsible for routine observations in the wards.

"In addition to the assistant pathologist and assistant clinical pathologist, there should be an assistant chemical pathologist to assist the clinicians with the problems that arise in the diagnosis of cases requiring investigation from the chemical standpoint. The investigations would be carried out in the wards, side-room, clinical laboratory, and pathological department. Where necessary, further inquiries might be continued in the laboratories of the University and Royal College of Physicians."

The assistant physicians are of opinion that unless steps are taken to correct the existing defects in the equipment referred to above, the teaching of clinical medicine will remain unsatisfactory.

5. Radiography.-The general arrangements of the department call for revision in the interest both of the patient and the student. Amplification of the facilities for diagnosis and treatment are necessary, and increased opportunities for regular instruction of the students ought to be made.

6. Ward for Alcoholism, Poisoning, and Mental Derangement.-The 
clinical material in this ward should be more utilised for teaching. Some arrangement is desirable whereby the University Lecturer on Mental Diseases might be associated with the Infirmary in a consultative capacity, and, acting in co-operation with the physician in charge, give an occasional lecture or clinique on the mental cases that bulk largely in the ward. This would tend to bring the subject of mental disorders into closer touch with general medicine. It is also desirable that the indoor arrangements for this ward should be reorganised, a special ward for incipient mental cases being established.

If the general scheme outlined in the foregoing, regarding teaching arrangements and equipment, is brought into operation, the efficiency of the medical teaching will, in our view, be greatly increased. In addition to this, however, there will accrue the further advantage of really useful clinical records being obtained. It is probably no exaggeration to say that the clinical records of the medical cases in hospital are, from the point of view of progress in medical knowledge, of small value. For reasons we have touched upon, they are necessarily incomplete, and therefore can be of little use, either now or in the future, as an aid to advancing our knowledge of medicine. In the discussion on Pathology an account was given of the admirable arrangements that were made by the pathologist for teaching the student to correlate the post-mortem appearances with the clinical findings. It would clearly be a great advantage to the teaching in the school if some uniform plan could be arranged whereby the clinical records of cases could be made more serviceable both for present need and for future reference.

\section{DISCUSSION.}

Dr. Mackie White.-In Dundee we look upon ourselves as an offshoot of Edinburgh. We try to carry out the traditions which were instilled into us so many years ago. My colleague, Dr. Stalker, and myself have had the teaching of medicine there for some years. Our school has about twenty-five to thirty students in the two final years, and we still adhere to the system of having medicine for the first time in the fourth year, with one exception, that recently during the summer term of the third year the elements of physical diagnosis have been taught-the groundwork which Professor Russell has so strongly insisted upon as being necessary to clear the way for the teaching of clinical medicine. During our time together Dr. Stalker and I have taken the seniors and the juniors for bedside teaching alternately. By this means we can to a certain extent differentiate in regard to the kind of instruction to be given in our cliniques. Besides the bedside cliniques we give one lecture a week to the whole class, and there, of course, the juniors have perhaps just to pick up what they can, because we cannot give the most elementary instruction to the seniors. At the same time one must always remember that in the seniors you meet at times the most appalling ignorance of facts impressed again and again upon them. 
The papers we have listened to to-night seem to me to be extremely helpful in regard to the future of this school. The advantages of a small school like ours are evident enough, i.e. we know practically the capacity of every single student intimately, and are able in going round the wards. or in bedside teaching to direct our instruction to a certain extent towards individuals. Of course real individual teaching is impossible, i.e. the kind of teaching that the house physician gets when he is on for six months with a visiting physician. The ordinary house physician will frankly tell you that he has learned more in three months than in all his course before. Just now, when so many of our young medicals are called away to the war, we have to use very largely the senior students as house physicians, to their very great advantage in some respects, although in others it is a disadvantage. I have been in the way of giving three or four beds to each of the seniors, for which they are held responsible, for which they get up the cases, describe them to the class, do all the investigations that the house physician ordinarily does, and follow them in fact to the time of their discharge. It is certainly very useful to the men, and it is a method practically carried out by Sir William Osler in the Johns Hopkins Hospital. He had a chance of organising the teaching of medicine in the Johns Hopkins University from the very start, and in his book Equanimitas-one of the most charming books in medicine-he describes how in the third and fourth years-the final terms then-he arranged the scheme of teaching. Of course it was done regardless of expense. He had graduate assistants such as they have in Germany-men who had devoted several years of their lives to hospital work-and he utilised the out-patients in the way adumbrated in the papers to-night. We give the out-patient instruction in the fourth year-many think it would be better in the fifth year, because it ought not to be taught quite so systematically as the bedside teaching of the wards. Osler, of course, had a very efficient bacteriological and clinical pathological department, every student having his seat and his microscope, with opportunities for doing all sorts of clinical pathological investigations which are so frequently lacking here. That is a thing I think we should aim at in Dundee. I imagine you do so here.

Professor Harvey Litrilejohn.-The speakers to-night have to some
extent forgotten that we are confined in a very important direction. Our curriculum is a five-years' one, and unless that time is increased it is not possible to get everything we desire into it. We must do justice as far as we can to the various compulsory subjects which are put in that curriculum by the General Medical Council. We agree, I suppose, almost in toto with the scheme sketched out by Dr. Matthew, and for post-graduate teaching nothing could be more admirable. But is it possible to utilise all the elementary suggested for the Infirmary in his paper in the teaching of the it is. Our medicine we have to give our undergraduates? I do not think disposal, the essential be to teach them, in the short space of time at our possible the essential facts of medicine, and try and make them as far as

I do nood, reliable general practitioners.

but this is think it very much matters in regard to systematic medicinethe third or the fo course, to what the pathologist may say-whether it is in medicine to the fourth year. At the special request of the teachers of clinical fourth to the third Faculty the transposition of medicine was made from the fourth to the third year, one of the reasons given being that it would combine 
better with pathology than did surgery in the third year. I personally agree that medicine is better placed in the third year, and that the student ought then to get an insight into the elements of medicine, which will be of great advantage to him afterwards in connection with his study of surgical cases. It is no argument to say that it is too early in his course, and that by the time the final examination comes he has forgotten it. $\mathrm{He}$ ought not to have forgotten it, because, though he has his systematic medicine in the third winter, the whole of his time thereafter is associated with clinical medicine-and clinical medicine $i s$ the teaching of medicine. Systematic medicine ought simply to be giving the student a general outline of various diseases. My idea of systematic lecturing is that the lecturer should be simply like a guide taking a number of people round a picture-gallery, devoting the greater part of the time to those pictures which are standards in art. He should point out the characters of all the pictures, but devote special attention to those which really may be taken as outstanding types. By this means the student would get a view of the whole subject, not sufficient to make him a complete physician, but sufficient to carry him on throughout the rest of his curriculum, and to be a material help in what one might say was the more advanced teaching which he gets when he attends clinical medicine. I, therefore, do not agree that in taking systematic lectures in the third year the student loses touch with the subject for his final examination; he continues the study by attending nine, and generally twelve,
months of clinical medicine.

In regard to clinical medicine, had it not been for the war a great many of the suggestions made here to-night would have been carried out. Indeed the scheme mentioned by Dr. Gulland was in the minds of many of us long before it was put on paper, and it was the intention of the Faculty of Medicine to try and effect more efficient teaching all round, especially in the clinical
subjects.

Too little is made of the great advantages which already exist for clinical medicine instruction. I do not think they are fully appreciated : we have in the Infirmary seven separate units, consisting of a chief physician, an assistant physician, a tutor, and house physicians. It is now a most important factor that each such unit is complete in itself, and that the number of students is limited as far as possible, so that a staff of at any rate four members have only a certain number of students under their control for clinical instruction. It is up to us, therefore, to see that those students are efficiently taught. It is a great pity that almost every student now, when asked what he is going to do after he graduates, says at once that he is going in for surgery. Why? Because he has been enthused by the surgeons. I think it is to be regretted that the physicians cannot get such a hold of the student of the present day as to make him as keen on the practice of medicine. I cannot help believing that this circumstance has something to do with the way that clinical medicine is taught. We are told in Dr. Matthew's paper that he wants more money spent on clinical apparatus, but he does not mention that $£ 600$ was paid by the university four years ago for providing clinical appliances, microscopes, etc., nor that special tutorial rooms at the request of the physicians were provided, equipped, and intended to be used in the elementary teaching of the students in testing urines and other
chemical methods. 
Dr. Gulland lays too much stress, in my opinion, for a professor of medicine, on examinations. We must not bow to the desire of the student and give him lectures or notes which are going to be useful simply for examination purposes. It is the duty of the teachers to give him the teaching that they think best for him, without any thought as to the examination, and when the examination comes, to make it a practical one which will test. his knowledge fairly.

It is one of the great desires of the Faculty that we should get the Dispensaries to work in very close conjunction with the teaching of practical medicine in the university. It cannot be done without the loyal co-operation and help of the physicians who are attached to these institutions. It is a question of money, and very properly there must be some remuneration: one of the difficulties will be to provide sufficient remuneration. Still, I do hope that after the war we will be able to have a conference and try, all of us who are interested in the school, to put the Dispensary back again to the important place which it held in the practical training of our students.

DR. Thin.-We have heard a great deal to-night about the improvement. that ought to be made in the practice of physic. I speak from the point of view of the general practitioner, whose lifework it is to put into actual practice the lessons learned in the medical school, and to elaborate and improve them as he goes along. The scheme we have of giving one hundred lectures ought to be to a considerable extent scrapped. These lectures are a relic of mediæval times, when books were non-existent or were too expensive to be in the hands of students. Now, we have a number of quite good textbooks, any one of which might be used by the students as the basis of the work. A considerable amount of time could be saved if the student were made to utilise the text-book as it ought to be used. The time now used for the one hundred lectures might with more advantage be spent in the hospital, the ward, the clinical theatre, or the out-patient department. Particularly I would emphasise the necessity of the senior student being made to attend the out-patient department regularly. The men should learn at the outpatient department the mode of treatment of the minor complaints and of the beginnings of disease, the earliest features of the diseases of which they see the full-blown article later on in the wards. The student ought to get some training in certain aspects of psychology, apart from what is concerned with the department of the insane. While we teach the student all we can about the anatomy and the functions of the body, we leave out absolutely the functions of the brain and mind. These functions are a most important factor in the origin of many illnesses and in the treatment of the individual when ill. There are a great many ailments which may be called functional lines of and hysterical conditions which are only to be elucidated along the is no great chology. The method of attacking these at the present moment is no great credit to our profession.

Dr. Fleming. - I do not agree that we ought to have fewer than one hundred lectures, because I think that a course of systematic medicine should be a collection of types of disease which should be given to the student not necessarily before he enters the ward, but as a guide to him when he gets there, and no text-book can replace the remarks which a good lecturer on systematic medicine can make. If you are going to say that systematic 
medicine is not necessary, then obviously systematic surgery is not necessary ; systematic pathology-I do not know where you would end. You are going to eliminate the teacher except as a practical demonstrator. I used to believe that note-taking is bad, but I am certain that if you want to remember anything you will do so best if you write it down. I do not mean that the lecturer should dictate to the student, but I do think that good notes are essential. The association of the systematic and clinical teachers would be extremely valuable.

To my mind it is absolutely unsuitable that medicine should come in the third winter. If most of us were surgeons, I could see that surgery ought to hold the place it does in the fourth vinter ; but most of us are physicians, and unless we have a junior and a senior course of systematic medicine it is a mistake. Surgery appeals to the junior student, he likes putting on bandages and splints under direction, but the clinical teacher in medicine can also fascinate his students, and I do not agree that they are not enthusiastic
about medicine.

As to case-taking, I believe that if in the Dispensary, where the student gets the chance of having a number of cases under his care, the Dispensary doctor's attitude was to see that all these cases had reasonable notes made of them before the student got his certificate of attendance, he would be doing a great service. For junior students the physical signs and symptoms in health should be the first ground for clinical work, and after that should
come case-taking.

It is a pity that we have so many special subjects; many of them might far better be post-graduate. A specialist is apt to give the student far too much. It would not be a good thing to diminish the number of clinical lectures by making still more special subjects.

Dr. Chalmers Watson.-The unanimous views of the assistant physicians have been by arrangement so fully presented in Dr. Matthew's paper that there is little room for elaboration, but perhaps I may be allowed to enlarge very briefly some of the points made in that paper in the light of the interesting recommendations made by Professor Russell and Professor Gulland, and also of the remarks made by Professor Littlejohn.

It cannot be gainsaid that the status of the medical school depends infinitely more on the standard of efficiency set by the thirty clinical teachers of medicine and surgery than on the work of the relatively few teachers in the earlier systematic subjects. The first point that arises is, whether or not there has been any deterioration in the standard of efficiency in the school. When I compare the teaching and the work done by medical students twenty-five years ago-there were over one hundred students in Sir Thomas Fraser's clinique at that time-I an quite convinced that the interest which the students took in their work, the amount of time that they devoted to their practical work, and their practical efficiency on graduation, were considerably greater than at the present time. It is exceedingly difficult accurately to apportion the blame for this state of affairs. It is, in my opinion, due in part to defects in the teaching, and in part to the multiplication of classes and a lack of proper co-ordination of effort on the part of the teachers in relation to the student's curriculum.

There are numerous suggestions of a practical kind in Dr. Matthew's paper which, if effectively carried out, would in our view greatly increase 
the efficiency of the teaching. In the opinion of the assistant physicians one of the main factors which have contributed to the lessening of the standard of efficiency in teaching is the absence of adequate facilities for the diagnosis of disease, and for its treatment from the modern standpoint. The crux of our position is embodied in the statement that, "whereas there have been many important advances in our knowledge of the diagnosis and treatment of disease in recent years, there has been no corresponding development in the equipment and facilities available in the hospital:" Recent graduates of medicine, who have compared the facilities available and the teaching with those in other schools, have come quite correctly to the view that the teaching in their old school falls, in certain directions, materially short of modern requirements.

Professor Littlejohn has asked a very important question, viz. Is the scheme suggested in Dr. Matthew's paper a practical one for the teaching of medical students? In our view, it is not only possible but essential. One of the reasons for the absence of enthusiasm in medicine shown by medical students, to which Professor Littlejohn has referred, is the fact that the students are continuously seeing cases of chronic disease remaining in hospital for weeks or months, and them leaving very much in statu quo. We do not make adequate use of the methods of modern diagnosis as to the nature of these affections; we are too content to make use of the facilities for the diagnosis and treatment of these disorders which were available in our own student days. Personally, I do not wonder that the present-day young graduate wishes to direct his time and energy to surgery in preference to medicine.

We cannot discuss the subject of efficient teaching without reference to the subject of scientific research. Professor Gulland tells us that the modern text-book is no sooner issued than it is out of date because of the advances in modern medicine. In that statement we find a clear, a definite, and a correct expression of opinion, showing the interdependence of teaching and clinical research. Any discussion on the efficient teaching of medicine at the present time is therefore comparatively futile unless adequate consideration is given to this important subject.

I wish to refer to another point which bears directly on efficiency in teaching in the Edinburgh school. I think you will not get the maximum state of efficiency until you improve the status of the assistant physician. Until a few months ago the assistant physicians had no say whatever in the teaching arrangements of the school. Under such conditions a man of 45 or 50 years of age for the first time becomes an integral part of a system which he may think radically inefficient. Is it to be wondered at if he then succumbs along the line of least resistance-a line which is prejudicial to the interests of the school? This is a point of view which does not commend itself to our senior colleagues. Personally I can speak on it more freely because, but for the war, I would now be a senior physician. I am so impressed with the importance of this subject in relation to efficient teaching, that so long as the junior physicians make the claim for their complete inclusion on the Clinical Medicine Board, I will do everything possible to support their application. If it is competent for the committee of this Club to deal with any recommendations on the subject, I strongly urge that they put forward as a definite recommendation that lecturers of clinical medicine 
be ex-officio members of the Clinical Medicine Board. I am perfectly sure that would make for much greater efficiency, and that it would tend to promote in a fuller degree the co-operation which is required. That could be done without in the slightest degree infringing the supreme authority of the chief of the ward.

In consideration of the views expressed by the assistant physicians in Dr. Matthew's paper as to the important influence which our defective equipment and outlook generally has had on the efficiency in clinical teaching, I would like to ask Professor Russell whether he agrees with us that efficiency in teaching necessarily involves equipment of a modern kind; that we have been too long content with a standard of equipment which falls below the minimum required; and does he agree that he, like us, has important responsibilities in regard to the correction of these defects as quickly as
possible?

At the present time the Edinburgh school has a magnificent opportunity for reconstruction. That reconstruction will only attain a satisfactory level if a new atmosphere arises-one permeated by a spirit of progress. I have on many occasions discussed with my senior colleagues the problems raised in the paper, and I have never found any substantial difference of opinion between us. The curious thing is that nothing whatever is done either individually or collectively. In connection with all the schemes of reconstruction arising out of the war, a very important place must be given to medical education and the advance of medical science in its curative and preventive aspects, and if we are to make full use of our opportunities, we must seek to develop the new atmosphere required. If this is accomplished, the unique opportunities afforded the clinical teachers might surely go a long way to restoring the Edinburgh school to the proud position which it formerly occupied as the leading centre of medical education and medical practice in
the kingdom.

Dr. Logan Turner. - I feel it my duty to put in a word for the greater utilisation of the younger men in the school as teachers. Twelve years ago,
when I was appointed a senior sureon I at once saw that that part of the teargen in the Ear and Throat Department, and I had not any hesitation in teaching should be essentially developed, very nearly share and share alike with all my junior staff and making them me' out when I say that he has been utilised, I think Dr. Fraser will bear liked, in the teaching. Then as to the younger men perhaps more than he utilisation of the wards. We cannot expect men to having a share in the work unless they also get the facilities they deserve. of research, to my mind the good teacher deserve. As regards the question own research, and in the Ear and Throat Department this has beenducts his out in a valuable way. One has not confined one's desire to encourage researied in the assistant staff; the clinical assistants also as far as possible have been encouraged to do research work, and up to the outbreak of war they have contributed annually to the Reports of the Department. If this can be done in a small department, it can surely be done in the larger departments of the Infirmary. I hold that the school would benefit by reducing the size of the cliniques, by training men while they are still comparatively young into
better teachers more fitted for senior

Dr. RaIry.--I agree with Professor Russell that the senior teachers might 
in ordinary times take a larger share in teaching the elements than they do. I have tried that with great advantage. We quite realise the importance of complete co-ordination; and I would only say that, as an assistant physician who, owing to various accidental causes, has worked under six chiefs in his time, the majority of these were quite willing to utilise one to the full. A little more systematising of clinical medicine would be an advantage. I was struck in Vienna with the way in which they managed to run systematic courses in clinical medicine and in the special subjects. Co-ordination and co-operation in the different wards might help us to a considerable extent in developing that side. We are too much individual units in the Infirmary. When I was attached to the Sick Children's Hospital I felt very much that there was a different atmosphere-that the staff, in fact, worked all the time as a whole.

There is a very definite place for the systematic lectures, but I do not know that the present system, to which we are more or less bound by ordinances and other things, is altogether ideal. I would much prefer, as in certain other subjects, to see medicine divided so that juniors might attend three days a week for thirty or forty lectures, and seniors attend two days a week; so that the juniors would get the fundamental details given them, and then the senior course could fill in gaps and treat of matters which would be much more appreciated by students of more clinical experience than thirdyear men can possibly have had.

With the paper by Dr. Matthew I am practically in accord. We do want to bring in the special departments-balneology, massage, and so on-and to make them much more practically in evidence for the students. Before long we may get a certain amount done in that direction.

With regard to the preference to surgery over medicine, it is dangled in front of students that in surgery the fees are bigger, which constitutes a definite point in its favour, but there is also the fact that somehow there is more of a feeling of progress in surgery of late years than we can claim in medicine. I do not think that will continue indefinitely, and I hope that before long the physicians will have their innings again.

In the ward for delirious patients, arrangements should certainly in some respects be altered. It does not follow by any means that the teaching of psychological medicine in that ward can be conducted by a man whose interests may lie in any other branch of medicine. It would be well to associate with him some man with special experience in work of this kind.

Mr. MiLes.-Professor Russell very rightly regretted that the student did not reach clinical work until the third year, when he arrived in what the professor described as a "virgin state of mind" as to all matters clinical. Is it not possible that the student should enter the hospital somehow before his third year? It is absurd that after studying anatomy and physiology for two years he should arrive at the hospital knowing nothing whatever about the bearing of these things on medicine. Professor Russell said that the systematic lecture should be something very much better than a text-book; I would put it that it should be something very different from a text-book. Each has its proper rôle in the teaching of students. The lecturer should expound the text-book, and to that extent be better than it, but the two are essentially different. The taking of notes can be of little use ; the student so often takes down the wrong things, and would get at the subject much 
better from a text-book. Provide the text-book and expound it-there you have the proper combination.

Professor Ritchie.-The discussion to-night has dealt largely with two different things - the present teaching of medicine and its defects, and the ideal teaching of medicine. With regard to the first, we are undoubtedly at the present time handicapped in various ways-one of these being that medical students do not all commence their course at the same time. Some commence three months before others, and ultimately these two groups come together and dealing with them constitutes a serious practical problem. One of the things the committee of this Club will have to consider in their report is whether the time has not come for a reconsideration of this matter with a view to laying down one curriculum which shall be commenced at a certain time of the year, and which shall be followed in an orderly way throughout. One of the results of the present unfortunate defect is that, if the student commences his work in the summer term, he has practically nothing to do in his fourth summer, and a great many of our students-as is well known-go away from the university for three months because they have not sufficient employment here. Might not this summer be used for giving the men instruction in those special subjects as raised in the paper by the assistant physicians, thus converting what is largely at the present time a waste period into a period fruitful in turning out better clinicians?

Various speakers have raised the question of the fact that the students have to crowd too much work into a very brief space of time, and that therefore they have not the opportunities for clinical observation which they ought to have. I remember eight or nine years ago, when this subject was last discussed by the Club, that the committee, of which I was a member, had evidence of a great change which had come over the practice of students of the school since they (the members of the committee) had been students themselves, viz. that the students did not spend so much time in the Infirmary in the evening as formerly. I have not heard whether this has. been altered, but I fancy not, and I think that the Managers of the Royal Infirmary cannot be considered entirely blameless in the matter; nor can the teachers of the medical school be considered blameless, in that at the time when the managers limited the hours of attendance of students in the evening they did not make a strong protest against the change. When I was a student we spent long periods in the Infirmary in the evening. In many respects they were the most fruitful periods of our clinical work ; we came round and made observations for ourselves on the patients, and this tended also to make the position of the house physician or house surgeon a more important one, because he was expected by his chief to take an integral part in the teaching of the students in directing them in these observations. This point should be borne in mind with a view to some return to the old system. The argument that the patients suffer will not hold water. The patients used to be glad to see the students in the evening; it relieved the tedium of their existence to a certain degree, and I am certain that when the wards were properly under the control of a competent house physician, no harm resulted
to the patients.

Some of these points may be remedied to a certain extent, and, I hope, more time given to the student in his earlier years for his clinical work and for following up those developments which have been referred to in 
Dr. Matthew's paper. I trust that the earlier part of the course may be lightened of some of the scientific work, and that we may gain in that way sufficient time, even in the short period of five years, to send out the student a more competent general practitioner than is the case to-day. This is a matter which requires immediate attention. It is a uniform experience that, so far as the scientific teaching of medicine is concerned, the medical student of Edinburgh still goes out into the world probably the best equipped student as compared with any other of the medical schools.

With regard to what might be called the ideal course in medicine, we all agree that the lines laid down by Dr. Matthew in his paper are the lines which must be followed in the future development of the school. We must have better equipment and a better organised system of the teaching of special subjects. I do not think it is inconsistent with our turning out general practitioners that we should give them a great deal more experience of special methods than we do at present. Certainly the development of such a scheme as Dr. Matthew has sketched would inevitably lead to a greater development in research in medicine in this school, without which development the health of the school cannot be maintained.

At the present time there are two great obstacles to the development of the school. The first is the question of money. When the proposals brought forward by the assistant physicians were originally submitted to the Board of Managers of the Royal Infirmary, the managers were in the greatest sympathy with them. If they had had the money they would undoubtedly have proceeded at once to the reconstruction of the medical electric department, to the reconstruction of the balneological department, and they would have provided a department of physical therapeutics. But it was pointed out that to embark upon this scheme would probably require $£ 60,000$, and the managers simply had not this money, and saw no prospect of getting it. The second is the size of the school. That is a difficult problem. There is no doubt that the Edinburgh school would be more efficient if it had fewer students. The clinical facilities in Edinburgh are, after all, limited. Further, the teaching staff of the Infirmary must, from the fact that the population of Edinburgh is not very great and from the fact that Edinburgh is not an industrial centre, be drawn from only the limited number of men available for teaching posts, so long as such men must rely on private practice for a livelihood. If this school is to become the greatest medical school in the British Empire, we must take such steps as shall result in our getting, not an increase of numbers, but an improved type of students into the school. We are all at one in believing that the time has come when fresh developments must be made, and the discussion to-night has laid down in a broad way the lines that those developments must follow.

Dr. C. B. Ker.-Do Dr. Matthew and the assistant physicians think that the addition of extra side-room work, with perhaps more or less complicated apparatus and things of that sort, will not necessitate a longer curriculum, because some of us think that there is little enough time, so far as we can judge, for purely clinical and bedside instruction? From my own experience, my view is that the student is sometimes apt to get hypnotised by elaborate side-room methods to the exclusion of the patient himself. We should all be glad to see an extension of the things the assistant physicians are asking for if they do not consist in an addition to the curriculum. I think if there 

is any subject in which the whole hundred lectures are required it is
medicine.

Dr. James Miller.-One has come in contact with case-taking as a resident, and more recently in the department of morbid anatomy under the new system of teaching that subject, and one's conclusion in regard to the taking of cases is that it is unsatisfactory. That results from two main causes - one a want of interest on the part of the student himself, and the other a want of superintendence on the part of someone skilled. The superintendence which he gets is that of the house physician, unless his case comes up for a clinique, when it gets criticised by the physician; yet that case will form practically the only record which there is for the purposes of the Infirmary. The suggestion I would make as regards this state of affairs is first of all that the students should have a certain number of cases to take, and the marks they get for them will count in the class of systematic medicine and in the professional examination. Further, that associated with the case-taking there should be a summary or critical survey of the whole case co-ordination-the pathological, clinical, and therapeutic aspects.

Dr. Ivy Mackenzie.-Professor Russell began with a clear and simple exposition of the method in which the subject ought to be taught, and we have wandered from that into the region of administration. It would be a very good thing for any medical school to be organised along the lines suggested by Dr. Matthew; but I am not sure that it would be of the greatest benefit to the students, because the student ought to be taught only the elements of medicine and the method of looking at medical problems very early in his course. I do not see why that should not begin in the first year of medicine. A student ought to be saturated with the impressions that come from looking at sick people, and that cannot be begun too early in his course. He ought to be taught very early how to look at the pupils, at the skin, at the respirations-the things that the nurse has to put down in her day and night report. Any physician who has a good sister in a ward knows how much she knows about medicine without knowing anything about the technical terms used in pathology.

With regard to the question of systematic lectures, looking back on my own experience, I remember that one of my lecturers held his ordinary clinical lectures two or three days a week. He then gave his special systematic lecture, and in it he dealt in a systematic fashion with the subject which he had been demonstrating in its minute details during the rest of the week. That is my idea of systematic work. Dr. Gulland could not go over the subject in three hundred lectures in a way to satisfy himself. In a few lectures he has to deal with the subject in a manner which will produce such an impression on the student that when he goes out into the world he will have a definite method of looking at illness.

Dr. Thin suggested that the students ought to be taught psychological medicine. That is a most important thing. Psychological medicine as a rule is devoted to people who are hopelessly insane, and the student is not sufficiently impressed with the fact that there is a very definite distinction between disease and illness, i.e. that an anatomical change is not reflected every time in the same form of illness, that every complaint referable to an anatomical change has first of all to come through the consciousness of the sufferer; and the students in the practice of their art ought to be taught that 
it is their business to connect the nature of the illness with the brain, through which it comes. The psychological element of suffering comes into the most chronic maladies.

With regard to the relation of pathology to clinical medicine, I think, speaking from the point of view of clinical medicine, that on the staff of our wards there ought to be one member definitely associated with the pathology department. It is the case in some of the London hospitals that one of the juniors takes the assistant pathological work and helps the pathologist in the post-mortems that come from the wards; he assists the professor of pathology, and demonstrates to the students the relations between the pathological changes and the clinical phenomena observed in the wards.

Professor Lorrain Sмith.-The teaching of physiology might as far as possible be brought into the Infirmary and brought to bear on the cases there, so that it could be a real introduction to medicine. The same should be the case with anatomy and pathology. We have tried to carry out this co-ordination lately by making the main part of our course the teaching of how the story of disease in a given case is to be read in pathology in correspondence with the clinical observations and history of the case, making the study of pathology as far as possible an introduction to the subjects of medicine and surgery. By thus co-ordinating the work of these departments a great deal of introductory matter could be got over, and physiology, anatomy, and pathology could be made more interesting to the students, who would arrive at medicine not unfamiliar with the living patient. We have found in pathology that systematic lectures are of comparatively little importance to the student until he has a basis on which to build. To give a course of systematic lectures, and say, "Those are the general principles; go and apply them," is more or less a futile effort in the direction of teaching. We have found it more successful to give the men a very short introduction to the subject, and then send them to study that subject under expert teachers in living cases. Having studied it so, they come back and listen to a systematic lecture such as that to which Dr. Ivy Mackenzie has referred. I should like to suggest that in teaching pathology and medicine together we should have the co-ordination which I think every teacher has mentioned between the wards and the pathology department, the physiology department-indeed, every department possible. We should have our introductory course of lectures, say on the heart, and then adjourn to the wards to study heart cases there, and after our students have seen a series of heart cases both pathologically and clinically, we should reassemble the matter in their systematic course and expound what science has to say in the interpretation of these cases. I should like to hear what Professor Russell and Dr. Gulland would say to this method of teaching. As for reading, of course there is a large percentage of men who stubbornly refuse to read. But the better men seem to read everything: one is sometimes overwhelmed by the amount they get through. I firmly believe that, without providing the concrete basis on which to build systematic teaching, systematic teaching is to a large extent a futile effort as far as most of the students are concerned.

Professor Russeli said in reply.-There was quite a difference of opinion as to the transposition of medicine and surgery in the curriculum. My experience is that this new arrangement has not been difficult. But that is perhaps because I have the advantage of having been trained as a pathologist 
as well as a physician, and that I never think of teaching medicine without in the first place clearly, however briefly, pointing out the pathological condition that is giving rise to the symptoms and to the physical phenomena.

The alteration suggested by Dr. Gulland is a good one, viz. that systematic medicine might be broken up into two courses, and that there might be a rapid survey of the various systems during the first term that the student is at clinical medicine.

With reference to Dr. Ritchie's remarks, there is a great deal to be said in favour of the University Court determining that students should begin their course either in winter or in summer. I say, let them begin in winter. The student who begins in winter and has done human anatomy comes to zoology with a much wider understanding and derives more benefit from it. They might begin their clinical medicine in the summer after the second winter. With a knowledge of physiology and anatomy, and with very elementary instruction in pathology, there is not much difficulty in teaching them physical signs during a single term. I lay strong emphasis upon the fact, however, that that cannot be done to a class of more than twenty or twenty-five. In the old days we went a great deal more to the Infirmary in the evening. The time of the student was not nearly so occupied as it is now. My contention has always been that with the suggested extra year much more might be done in this direction. The enthusiasm of the men for surgery has been very largely the result of the enormous advance made in abdominal surgery, which has overshadowed any advance in medicine since Lister's introduction of antiseptic medicine and surgery. Also the operative procedure appeals to the student because he likes to use his hands. But I can assure you that my students have been very enthusiastic this winter, owing perhaps to the intensive teaching in medicine that $I$ have been able to give them during the first term, and I shall be very surprised if I have not given them such a view of medical methods and systems as will keep their fancy attracted to medicine instead of drawing them away to the glories of surgical operation.

DR. Gulland said in reply.-The student will read if you interest him in the subject, but he will not deliberately read through a text-book for the sake of mental improvement. It was interesting to me to find that the assistant physicians and the Faculty have come to practically the same finding as to the way in which the services of the assistant physician should be utilised. As regards the systematic teaching, I should be thankful to have the number of lectures diminished, but I cannot see that it is altogether necessary to have a separate course on dietetics. Medical ethics are taught by the professor of medical jurisprudence. As regards the question of hospital equipment, the physicians are entirely in sympathy with the assistant physicians. There are a great many things in the matter of equipment that must be done.

The co-ordination of subjects as suggested to-night is a delightful prospect. The real difficulty just now with the teaching of physiology and anatomy is that the really important points are not impressed upon the students. That the anatomists should have the long time that they do have, and succeed in getting no more than they do out of the students is unfortunate, and the same is true of physiology. I think the teaching of pathology is most admirable, but my point is this, that you make it so interesting that it draws. the students' attention away from clinical medicine.

Professor Lorrain Smith.-It is directing it towards it. 